\title{
ANALISA QUALITY OF SERVICE LAYANAN VIDEO CALL BERBASIS INTERNET PROTOCOL MULTI MEDIA SUBSYSTEM PADA JARINGAN IP VERSI 6
}

\author{
Bongga Arifwidodo ${ }^{1}$, Syahriful Ikhwan ${ }^{2}$
}

${ }^{1}$ Program Studi S1 Teknik Telekomunikasi, Institut Teknologi Telkom Purwokerto

${ }^{2}$ Program Studi D3Teknik Telekomunikasi, Institut Teknologi Telkom Purwokerto

\section{Informasi Makalah}

Dikirim, 16 April 2019

Direvisi, 20 Agustus 2019

Diterima, 5 September 2019

\section{Kata Kunci:}

IMS

IP versi 6

Qos

Video call

\section{INTISARI}

Tidak bisa dipungkiri perkembangan teknologi saat ini begitu pesat, khususnya perkembangan teknologi dibidang telekomunikasi. Sehingga semakin memberikan layanan kemudahan untuk melakukan aktivitas komunikasi. Salah satu layanan yang sedang berkembang Video Call. Layanan Video Call menjadi pilihan dalam melakukan komunikasi jarak jauh. Teknologi komunikasi Video Call menggunakan IP Multimedia Subsystem (IMS). IMS adalah sebuah sebuah arsitektur framework untuk mengirimkan layanan internet protokol multimedia. Arsitektur Framework dirancang agar mampu menyediakan layanan multimedia yang lebih kompetitif dengan tingkat mobilitas yang lebih tinggi dengan desain agar mampu dijalankan tanpa adanya batasan area maupun domain. Oleh karena itu seiring waktu berkurangnya alamat IP versi 4 IPv4) maka dikembangkanlah alamat IP versi 6 (IPv6). Pada penelitian ini melakukan pengujian dengan melakukan video call menggunakan Open IMS Core dan client pada jaringan backbone IP versi 4 dan IP versi 6 . Untuk jaringan backbone IP versi 6 menerapkan sistem tunneling pada topologinya. Skenario pengujian menghasilkan nilai sesuai standar Tiphon didapatkan kehandalanan komunikasi bernilai baik saat diuji pada beban trafik 0 Mbps, 5 Mbps, 10 Mbps dan 15 Mbps. Kemudian saat penambahan beban trafik 15 Mbps, nilai delay yang didapat mencapai 16,17031693 ms, nilai throughput 0,115 Mbps, nilai jitter 5,18897E-06 $\mathrm{ms}$, dan nilai packet loss sebesar 15,51\%. Dapat disimpulkan sesuai standar Tiphon, kualitas layanan video call, mencakup nilai delay, throughput, jitter dan packet loss termasuk kategori baik, akan tetapi pada packet loss masuk kategori cukup baik.

\section{ABSTRACT}

The development of technology today is so rapid, especially the development of technology in the field of telecommunications. So that it increasingly provides convenient services for conducting communication activities. One of the services that is developing Video Call. Video Call services are the choice in conducting long-distance communication. The communication technology uses IP Multimedia Subsystem (IMS). IMS is an architecture framework for sending multimedia, internet protocol services. The Framework architecture is designed to be able to provide more competitive multimedia services with a higher level of mobility with a design that is capable of being run without any restrictions on area or domain. Therefore, 
as IPv4 decreases over time, the IP address 6 (IPv6) is developed. In this study conducted a test by video call using Open IMS Core and clients on the IPv4 and IPv6 backbone networks. For IPv6 networks implemented a tunneling system on its topology. From the results of the testing scenario, according to Tiphon's standards, communication, reliability is valuable both when tested at traffic loads of $0 \mathrm{Mbps}, 5 \mathrm{Mbps}, 10 \mathrm{Mbps}$ and $15 \mathrm{Mbps}$. Then when the additional traffic load is $15 \mathrm{Mbps}$, the delay value obtained reaches $16,18 \mathrm{~ms}$, the throughput value is $0,115 \mathrm{Mbps}$, the jitter value is $5,18897 \mathrm{E}-06$ $\mathrm{ms}$, and the packet loss value is $15,51 \%$. It can be concluded according to Tiphon's standard, the quality of video call services, including the value of delay, throughput, jitter and packet loss, including good categories, but in packet loss the category is quite good.

\section{Korespondensi Penulis:}

Bongga Arifwidodo

Program Studi S1 Teknik Telekomunikasi

Institut Teknologi Telkom Purwokerto

JL. DI Panjaitan No.128 Purwokerto, 53147

Email: bongga@ittelkom-pwt.ac.id

\section{PENDAHULUAN}

Perkembangan teknologi saat ini begitu pesat, termasuk juga perkembangan teknologi dibidang telekomunikasi. Saat ini sistem komunikasi dengan menggunakan layanan video call seringkali menjadi pilihan dalam melakukan komunikasi jarak jauh. Video call merupakan panggilan dengan layar video dan mampu menangkap video (gambar) serta suara yang ditransmisikan. File video dan audio dialirkan secara real-time melalui jaringan internet. Kualitas layanan atau Quality of Service (QoS) dapat dilihat sebagai mekanisme untuk mencapai tingkat kinerja layanan pada jaringan. QoS dapat juga dipahami sebagai kemampuan jaringan untuk menangani trafik sehingga jaringan tersebut dapat mencapai tingkat layanan yang dibutuhkan. Berbagai cara dicoba agar layanan Video Call dapat dimanfaatkan secara maksimal. Mulai dari pemilihan codec sampai dengan penyediaan bandwidth yang besar [1].

Salah satu teknologi yang digunakan untuk melakukan komunikasi video call ialah IP Multimedia Subsystem (IMS). IP Multimedia Subsystem (IMS) merupakan teknologi yang mengarah pada konvergensi antara jaringan wireless dan wireline. IMS digunakan untuk jaringan mobile dengan layanan berbasis IP.Layanan yang ditawarkan IMS juga beragam, tidak hanya voice namun juga dapat berupa data dan layanan multimedia lainnya. Salah satu layanan yang didukung teknologi IMS adalah video conference. Video conference merupakan layanan yang dapat memungkinkan dilakukannya komunikasi berupa data, suara, dan gambar secara duplex atau dua arah dan bersifat real time. Video conference banyak dilakukan saat ini untuk komunikasi jarak jauh seperti tatap muka langsung dengan menggunakan komputer atau laptop yang sudah memiliki webcam, bahkan saat ini video conference sudah dapat dilakukan di mana saja dan kapan saja dengan menggunakan smartphone[2].

Techno Vol. 20, No. 2, Oktober 2019: $95-104$ 
Next Generation Network (NGN) merupakan salah satu teknologi masa depan yang memberikan layanan berupa suara, data, multimedia, dan internet yang mengacu pada konvergensi layanan berbasis IP. Sebuah teknologi yang mendukung konsep konvergensi berbasis IP adalah IP Multimedia Subsystem (IMS). UMTS merupakan salah satu teknologi bergerak seluler generasi ke tiga (3G) yang sebagian besar masyarakat gunakan karena rata-rata masyarakat sudah menggunakan gadget yang mendukung jaringan 3G. Video conference merupakan layanan yang sensitif terhadap delay sehingga perlu dilakukan analisis QoS. Pada penelitian ini dilakukan simulasi dan analisis QoS video conference pada jaringan IMS-UMTS[3].

Penggunaan IPv6 adalah solusi yang tepat untuk menopang aktifitas internet saat ini. Banyak keuntungan yang dapat diambil dari penggunaan IPv6 yaitu alokasi address yang lebih banyak, auto configuration address, adanya traffic class dan flow label untuk mendukung aplikasi real time, mobile IP, IP sec, tetapi meskipun sudah diketahui penggunaan IPv6 masih sangat minim, untuk itu perlu diadakan penelitian yang berkaitan dengan penerapan IPv6[4]. Rata-rata tingkat kesiapan beberapa penyelenggara interenet di Indonesia berkisar pada level 2 atau pada tingkat aware yaitu penyelengara internet paham akan perubahan ke IPv6 tetapi belum melakukan implementasi[5].

Penelitian ini fokus pada pengembangan layanan video call, kemudian layanan tersebut dilewatkan melalui arsitektur jaringan IMS yang dibangun dengan menggunakan sistem pengalamatan IPv4 dan IPv6. Skenario yang digunakan dalam penelitian ini adalah memberikan beberapa beban trafik pada uji layanan video call baik di alamat IPv4 maupun IPv6. Beban trafik yang diberikan diantaranya adalah 0 Mbps, 5 Mbps, 10 Mbps, 15 Mbps. Parameter QoS yang digunakan dalam mengetahui kualitas dari suatu jaringan adalah delay, jitter, throughput, dan packet loss.

\section{METODOLOGI PENELITIAN}

\subsection{Diagram Alir Penelitian}

Dalam penelitian analisa quality of service layanan video call berbasis IP IMS pada IP versi 4 atau IP versi 6, akan menggunakan empat skenario beban trafik. Alir pertama yaitu persiapan perangkat penelitian, pada langkah ini jumlah perangkat yang digunakan adalah 4 unit personal computer (PC), satu unit yang digunakan sebagai server Open IMS Core, satu unit PC yang digunakan sebagai media routing dengan aplikasi GNS3, dan dua unit laptop yang digunakan sebagai client atau yang melakukan proses video call. Diagram alir penelitian dapat dilihat pada Gambar 1 di bawah ini : 


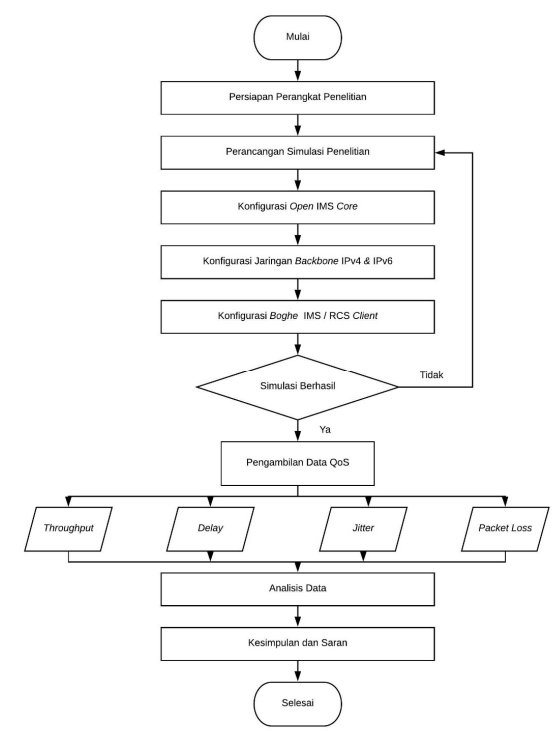

Gambar 1. Diagram Alir Penelitian

\subsection{Konfigurasi Open IMS Core}

IP Multimedia Subsystem (IMS) merupakan kerangka arsitektur jaringan yang memungkinkan untuk memberikan layanan berbasis IP, dimana memungkinkan menggabungkan layanan suara, video, data, serta jaringan bergerak hanya dengan memanfaatkan satu infrastruktur IP[4]. Konfigurasi Open IMS Core dilakukan pada operating system Ubuntu 14.04 LTS. Konfigurasi routing menggunakan OS Windows 10 sebagai jaringan backbone IPv4 dan IPv6. Aplikasi Boghe IMS/RCS Client sebagai media komunikasi antar client menggunakan OS Windows 7. Arsitektur konfigurasi perangkat simulasi jaringan dapat dilihat pada Gambar 2 di bawah ini :

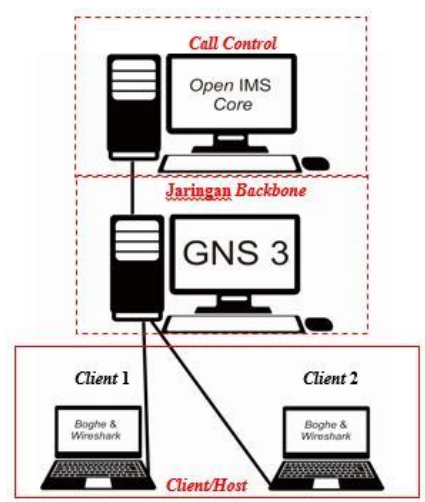

Gambar 2. Arsitektur konfigurasi perangkat.

\subsection{Simulasi Komunikasi Video Call}

Kemudian tahapan selanjutnya adalah melakukan simulasi komunikasi video call berbasis Open IMS Core pada jaringan backbone IPv4 dan IPv6 dengan beberapa variasi penambahan beban trafik mulai 0 Mbps, 5 Mbps, 10 Mbps dan 15 Mbps. Pengambilan paramater pengujian dilakukan sebanyak 30 kali. Skenario pengujian komunikasi Video Call dapat dilihat pada Tabel 1 di bawah ini : 
Tabel 1. Skenario Simulasi

\begin{tabular}{|c|c|c|c|c|}
\hline Skenario & Layanan & BebanTrafik & $\begin{array}{l}\text { Jaringan } \\
\text { Backbone }\end{array}$ & Parameter \\
\hline \multirow{3}{*}{ Skenario 1} & \multirow{8}{*}{ Video Call } & 0 & \multirow{4}{*}{ IPv4 } & \multirow{8}{*}{$\begin{array}{l}\text { Delay, Jitter, } \\
\text { Throughput dan } \\
\text { Packet loss }\end{array}$} \\
\hline & & $5 \mathrm{Mbps}$ & & \\
\hline & & $10 \mathrm{Mbps}$ & & \\
\hline \multirow{5}{*}{ Skenario 2} & & $15 \mathrm{Mbps}$ & & \\
\hline & & 0 & \multirow{4}{*}{ IPv6 } & \\
\hline & & $5 \mathrm{Mbps}$ & & \\
\hline & & $10 \mathrm{Mbps}$ & & \\
\hline & & $15 \mathrm{Mbps}$ & & \\
\hline
\end{tabular}

\subsection{Quality of Service}

Quality of Service (Qos) merupakan metode pengukuran tentang seberapa baik jaringan dan merupakan suatu usaha untuk mendefinisikan karakter dan sifat dari suatu service. QoS digunakan untuk mengukur beberapa atribut kinerja yang telah dispesifikasikan dengan suatu service [6] Pengukuran tentang seberapa baik jaringan serta merupakan suatu usaha untuk mendefinisikan karakteristik dan sifat dari satu layana dapat menggunakan metode QoS sesuai dengan standar Tiphon. Parameter QoS (quality of service) terdiri dari:

\section{a. Throughput :}

Throughtput adalah nilai rata - rata pengsiriman yang sukses melalui saluran telekomunikasi dalam suatu pengiriman. Throughtput diukur dalam satuan bit per second (bps atau bit/s). Rumus menghitung throughtput ditunjukkan pada persamaan 2.1 [7]

$$
\text { Throughtput }(\mathrm{bps})=\frac{\text { Packet Data yang diterima }(\text { bit })}{\text { Waktu Pengiriman Packet }(\text { second })}(2.1)
$$

\section{b. Delay :}

Delay adalah permasalahan umum yang terjadi pada jaringan telekomunikasi. Delay merupakan waktu yang diperlukan sebuah paket untuk melakukan perjalanan dari pengiriman ke penerima. Rumus untuk menghitung delay ditunjukkan pada persamaan 2.2 [7].

$$
\text { Delay Rata }- \text { Rata }=\frac{\text { Total Delay }}{\text { Total Paket yang diterima }}
$$

Klasifikasi standarisasi delay berdasarkan standar TIPHON [9] ditunjukkan pada Tabel 2.1. 
Tabel 2. 1 Klasifikasi standarisasi delay

\begin{tabular}{ccc}
\hline No & Kategori & Besar $(\mathrm{ms})$ \\
\hline 1 & Sangat Baik & $<150$ \\
2 & Baik & $150-300$ \\
3 & Cukup Baik & $300-450$ \\
4 & Tidak Direkomendasikan & $>450$ \\
\hline
\end{tabular}

Nilai delay dikategorikan Sangat Baik jika mendapatkan kurang dari $150 \mathrm{~ms}$, bernilai Baik jika mendapatkan di antara $150 \mathrm{~ms}$ sampai dengan $300 \mathrm{~ms}$, bernilai Cukup Baik jika mendapatkan di antara 300 ms sampai dengan $450 \mathrm{~ms}$ dan jika mendapatkan lebih dari $450 \mathrm{~ms}$ maka tidak direkomendasikan untuk digunakan.

\section{c. Jitter :}

Jitter merupakan variasi delay yang terjadi akibat Panjang antrian dalam suatu pengelolahan data dan reassemble paket data di akhir pengiriman akibat kegagalan sebelumnya. Rumus menghitung Jitter ditunjukkan pada persamaan 2.3 [7].

$$
\text { Jitter }=\frac{(\text { delay } 2-\text { delay } 1)+(\text { delay } 3-\text { delay } 2)+\cdots+(\text { delay } n-\text { delay }(n-1))}{\text { Total Paket yang diterima }}(2.3)
$$

\section{d. Packet loss :}

Packet loss merupakan parameter yang menggambarkan kondisi yang menunjukkan jumlah paket yang hilang. Rumus untuk menghitung packet loss ditunjukkan pada persamaan 2.4 [17].

$$
\text { Packet Loss }=\frac{(\text { Paket data dikirim }- \text { paket data diterima }) \times 100 \%}{\text { paket data yang dikirim }}(2.4)
$$

Klasifikasi standarisasi packet loss berdasarkan standar TIPHON [9] ditunjukkan pada Tabel 2.2.

Tabel 2. 2 Klasifikasi standarisasi packet loss

\begin{tabular}{lll}
\hline No & Kategori & Besar (\%) \\
\hline 1 & Sangat Baik & $0-2$ \\
2 & Baik & $3-14$ \\
3 & Cukup Baik & $15-25$ \\
\hline
\end{tabular}




\section{HASIL DAN PEMBAHASAN}

Pada bagian ini, dijelaskan hasil penelitian serta pembahasan yang komprehensif. Hasil pengukuran Quality of Service (QoS) berdasarkan standar TIPHON[9]. Adapun parameter yang diamati ialah Delay, Throughput, Jitter dan Packet Loss.

\subsection{Delay}

Delay merupakan waktu yang dibutuhkan data untuk menempuh jarak dari asal ke tujuan. Beberapa faktor yang mempengaruhi nilai besarnya delay, seperti jarak, media fisik/transmisi, congesti hinggga waktu proses yang lama. Berdasarkan hasil pengujian didapatkan analisis berikut :

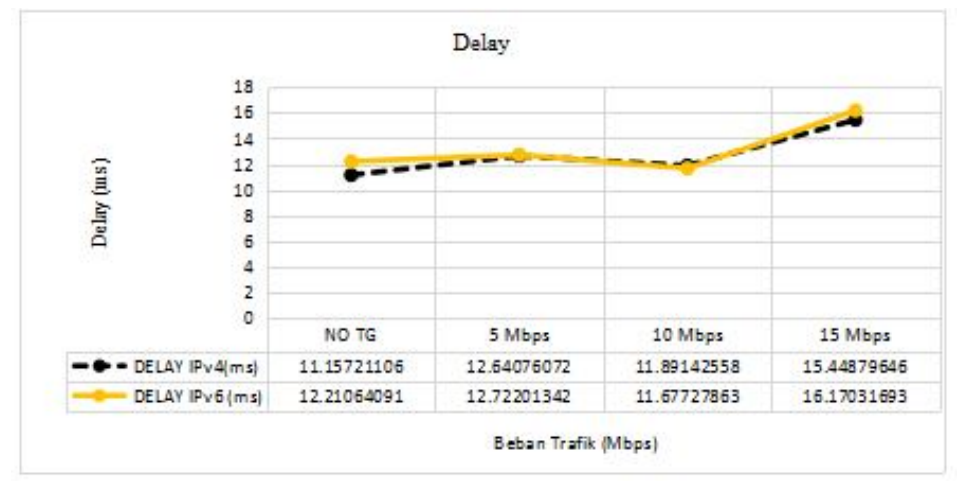

Grafik 1 Qos - Delay

Berdasarkan Grafik 1 di atas dapat dilihat hasil rata-rata delay layanan video call pada jaringan maka dapat diketahui bahwa nilai delay pada jaringan backbone IPv6 lebih tinggi dibanding dengan nilai delay jaringan backbone IPv4. Pada jaringan backbone IPv6 komunikasi data (layanan video call) berlangsung melewati jaringan tunneling yang menyebabkan jumlah paket data (bytes) dari protocol UDP semakin bertambah, karena semakin banyak paket yang dikirim maka semakin besar nilai delay.

\subsection{Throughput}

Jumlah total kedatangan paket yang sukses pada penelitian, diamati pada tujuan selama interval waktu tertentu dibagi oleh durasi interval waktu tersebut. Hasil pengujian data dapat dilihat pada Grafik 2 di bawah ini : 


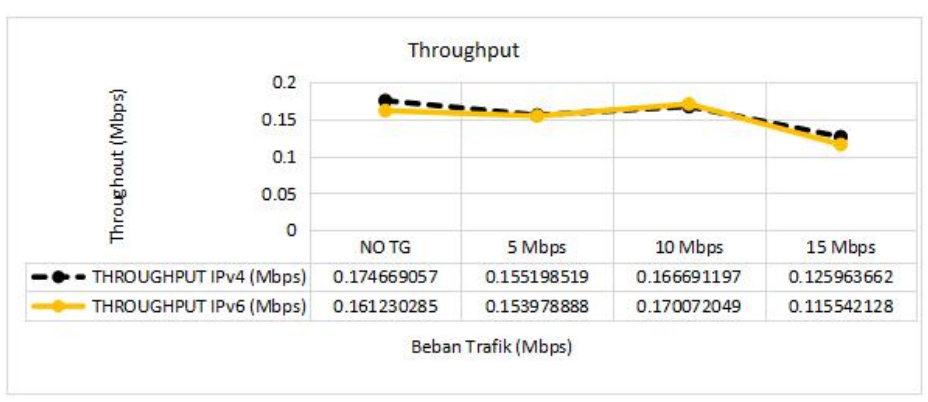

Grafik 1 Qos - Throughput

Berdasarkan gafrik rata-rata throughput yang didapat pada jaringan backbone IPv4 memiliki nilai throughput yang lebih besar yaitu 0,155630609 Mbps, dibandingkan dengan nilai throughput pada jaringan backbone IPv6 yaitu 0,150205838 Mbps. Hal ini disebabkan komunikasi video call pada jaringan backbone IPv6 melewati tunneling sehingga paket dari protocol UDP yang dikirim semakin bertambah. Oleh karena itu nilai thoughpout jaringan backbone IPv4 lebih tinggi dibandingkan nilai throughput jaringan backbone IPv6.

\subsection{Jitter}

Jitter biasanya disebut nilai variasi dari delay, berhubungan erat dengan latency, yang menunjukan banyaknya variasi delay pada transmisi data di jaringan. Hasil dapat dilihat pada grafik di bawah ini :

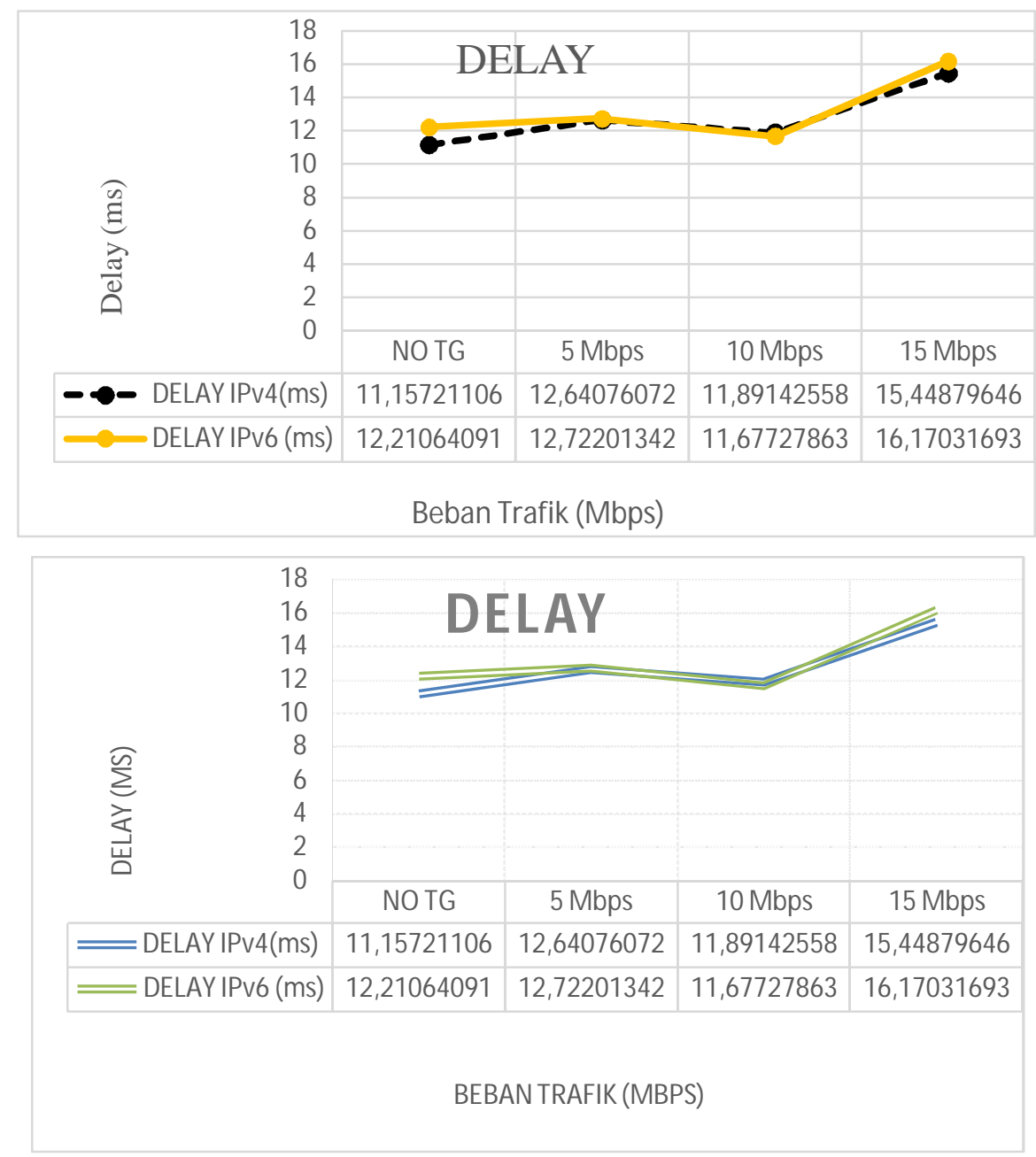

Techno Vol. 20, No. 2, Oktober 2019 : 95 - 104 


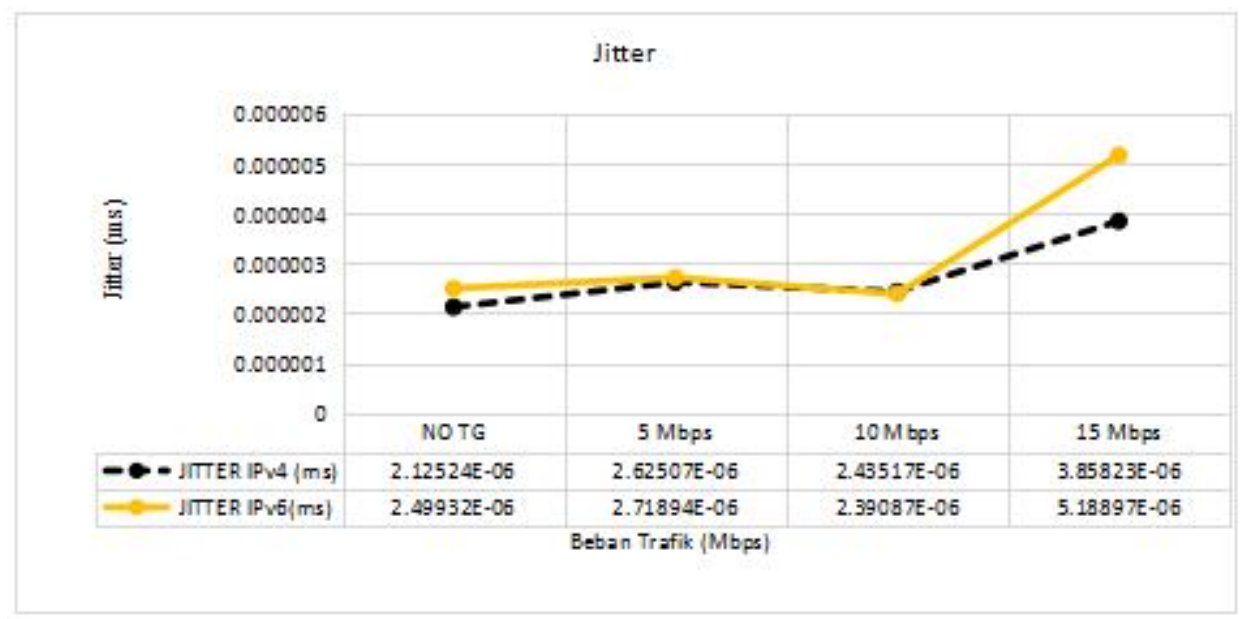

Variasi beban trafik yang dilakukan sebanyak 4 kali, skenario trafik tertinggi berada pada saat pembebanan trafik sebesar $20 \mathrm{Mbps}$, dengan nilai jitter 3,85823E-06 ms pada jaringan backbone IPv4, dan nilai jitter sebesar 5,18897E-06 ms pada jaringan backbone IPv6. Hal ini disebabkan oleh kejenuhan aliran trafik pada suatu jaringan diwaktu tertentu dan semakin padatnya aliran trafik yang disebabkan oleh perbedaan besar atau kecilnya paket yang dikirimkan. Pada jaringan backbone IPv6 memiliki peket data yang lebih besar dibandingkan dengan jaringan backbone IPv4.

\subsection{Packet Loss}

Merupakan suatu parameter yang menggambarkan suatu kondisi yang menunjukkan jumlah total paket yang hilang dapat terjadi karena collision dan congestion pada jaringan. Hasil grafik dapat dilihat :

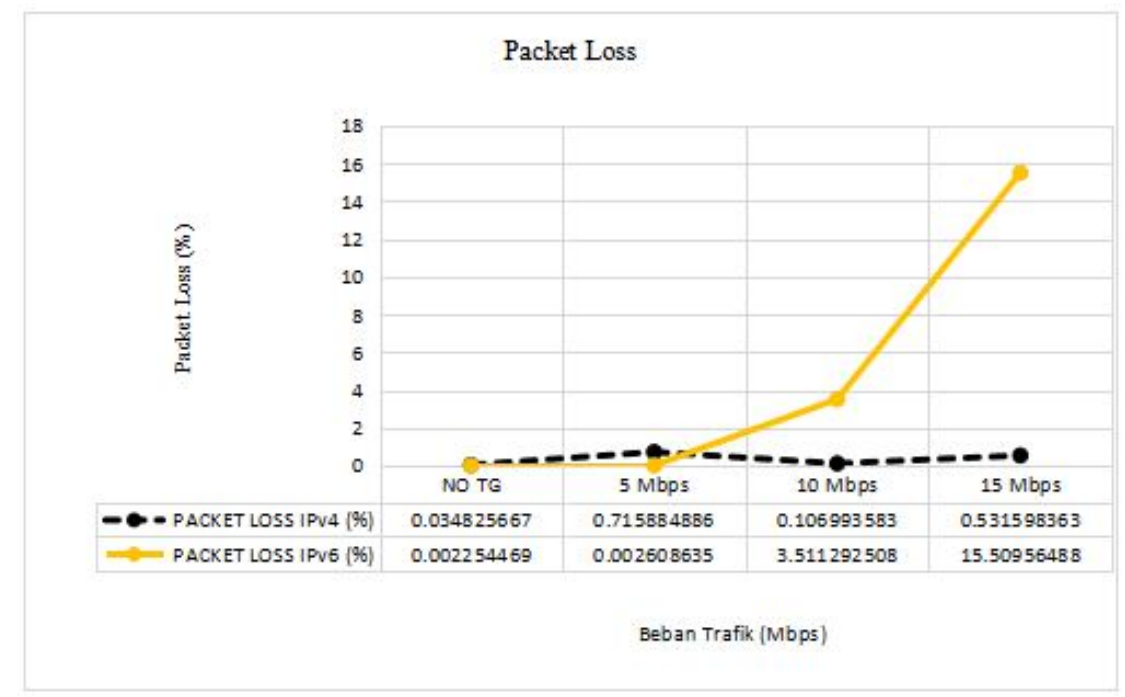

Kepadatan trafik merujuk pada besar paket yang dikirim dan beban trafik pada jaringan tersebut. Melihat besarnya paket yang dikirimkan, IPv6 mengirimkan paket dengan kapasitas lebih besar dibandingkan dengan jaringan IPv4, sehingga menyebabkan trafik pada jaringan jaringan IPv6 semakin padat, packet loss

Analisa Quality Of Service Layanan Video Call Berbasis Internet Protocol Multi Media Subsystem Pada Jaringan Ip Versi 6 (Bongga Arifwidodo) 
yang terukur menjadi lebih besar. Dari sisi beban trafik dapat kita lihat, semakin tinggi beban trafik yang diberikan maka semakin tinggi nilai packet loss yang terukur. Penyebabnya adalah padatnya aliran trafik yang membuat lebar pita jalur komunikasi semakin sempit, sehingga collision dan congestion tidak dapat dihindari.

\section{KESIMPULAN}

Perancangan layanan video call berbasis IP Multimedia Subsystem dengan network address yang berbeda pada jaringan IPv6 yang menggunakan metode tunneling dapat berjalan dengan baik. Berdasarkan hasil pembahasan dan analisis Quality of Service jaringan IPv4 dan IPv6 berbasis IP Multimedia Subsystem pada layanan video call, maka dapat diambil kesimpulan bahwa nilai $Q o S$ berdasarkan standar Thypon pada jaringan IP versi 4 masih lebih baik dibandingkan nilai $Q o S$ pada jaringan IP versi 6 dengan metode tunneling. Untuk pengembangan selanjutnya, penggunaan jaringan IP versi 6 dapat menggunakan metode selain metode tunneling agar memberikan gambaran hasil yang beragam.

\section{UCAPAN TERIMAKASIH}

Penulis mengucapakan Terima Kasih kepada segenap akademisi Fakultas Teknik Telekomunikasi dan Elektro di Institut Teknologi Telkom Purwokerto atas bantuan secara moral sehingga penulis dapat menyelesaikan karya ilmiah ini dengan baik dan benar.

\section{DAFTAR PUSTAKA}

[1] A. S. Nurul Luthfihadi, "Analisis Kualitas Layanan Video Call Menggunakan Codec H.263 dan H.264 Terhadap Lebar Pita Jaringan yang Tersedia," vol. 9, 2014.

[2] Rebecca Copeland, Converging NGN Wireline and Mobile 3G Network with IMS, Taylor \& Francis Group, U.S.A, 2009.

[3] Pranindito, D, "Simulasi dan Analisis QoS Video Conference Melalui Jaringan Interworking IMS UMTS Menggunakan Opnet", Jurnal Infotel. Vol.9, 2017.

[4] M. S. d. I. S. Maria Ulfa, "Analisa Perbandingan IPv4 dan IPv6 Dalam Membangun Sebuah Jaringan," pp. A-342, 2014.

[5] Riza Azmi, "Analisis Kematangan Implementasi Internet Protocol versi 6 (IPv6) di Indonesia dengan Interim Maturity Level (IML)”, BPOSTEL, 2011.

[6] "Internetworking Technology Handbook," 2005.

[7] B. A. Forouzan, Data Communications and Networking, Fourth Editi, 4th ed. 2007

[8] Eko Fajar Cahyadi, "Analisa Karakteristik Teori Antrian pada Jaringan IP Multimedia Subsystem (IMS) Menggunakan OPNET Modeler 14.5”, Jurnal INFOTEL. Vol 7, 2015.

[9] Tiphon, "Telecommunication And Internet Protocol Harmonization Over Network (Thipon) General Aspec Of Quality Of Service (Qos)", Dtr/Tiphon-05006, Vol. 2, 1999. 